\section{Post-traumatic stress, depression, and community integration a long time after whiplash injury}

\author{
Britt-Marie Stålnacke \\ Department of Community Medicine and \\ Rehabilitation (Rehabilitation Medicine), \\ Umeå University, Umeå, Sweden
}

\section{Abstract}

Psychological factors such as post-traumatic stress and depression may play an important role in the recovery after whiplash injuries. Difficulties in psychosocial functioning with limitations in everyday life may dominate for some time after the injury. Our study therefore investigates the relationships between pain, post-traumatic stress, depression, and community integration. A set of questionnaires was answered by 191 persons ( 88 men, 103 women) five years after a whiplash injury to assess pain intensity (visual analogue scale, VAS), whiplash-related symptoms, post-traumatic stress (impact of event scale, IES), depression (Beck depression inventory, BDIII), community integration (community integration questionnaire, CIQ), life satisfaction (LiSat-11). One or more depressive symptoms were reported by $74 \%$ of persons; $22 \%$ reported scores that were classified as mild to severe depression. The presence of at least one posttraumatic symptom was reported by $70 \%$ of persons, and $38 \%$ reported mild to severe stress. Total scores of community integration for women were statistically significantly higher than for men. The total VAS score was correlated positively to the IES $(\mathrm{r}=0.456, \mathrm{P}<0.456)$, the BDI $(r=0.646, \mathrm{P}<0.001)$, and negatively to the CIQ $(r=-0.300, P<0.001)$. These results highlight the view that a significant proportion of people experience both pain and psychological difficulties for a long time after a whiplash injury. These findings should be taken into consideration in the management of subjects with chronic whiplash symptoms and may support a multi-professional rehabilitation model that integrates physical, psychological, and psychosocial factors.

\section{Introduction}

Whiplash injuries are caused by a sudden acceleration or deceleration trauma that results in soft tissue injury or distortion of the neck. ${ }^{1}$ In Western countries the annual incidence varies from 100 to 320 per 100,000 inhabitants. $^{2}$ Most injuries occur in traffic accidents but other trauma mechanisms have been described..$^{1,3}$ The distortion of the neck usually decreases over subsequent days or weeks, but the injury may lead to a number of clinical symptoms known as whiplash-associated disorder (WAD). ${ }^{1}$ Although most subjects with acute WAD have a favorable outcome and recover within three months of the trauma, ${ }^{4} \mathrm{a}$ significant number of persons are reported to experience symptoms several years after the accident. ${ }^{2,56}$ The frequency of long-lasting symptoms and chronic WAD varies in the literature. Persistent neck-pain has been reported in $84-90 \%$ of persons one to two years after whiplash trauma. ${ }^{7}$ Some prognostic factors for chronic WAD such as age, female gender, and initial pain intensity have been identified, ${ }^{7,8}$ but it is still unclear why pain and related symptoms are involved in the persistence of symptoms and impairments after the trauma. Symptoms that may persist from the acute to chronic stage are neck pain, stiffness, headache, and dizziness. Other symptoms that may occur after the injury are fatigue, irritability, concentration and memory problems, sleep disturbances, and anxiety. ${ }^{1,4}$ These symptoms are not encountered solely in persons with WAD; they are also frequently reported by patients with mild traumatic brain injury or concussion, depression, ${ }^{9}$ and post-traumatic stress disorder. ${ }^{6}$ Moreover, several studies have shown that psychosocial factors such as post-traumatic stress and depression may play an important role in recovery after whiplash injuries. ${ }^{10}$

Although the severity of post-traumatic stress decreases with time, about one-third of traffic accident victims still suffer from posttraumatic stress reactions with anxiety and avoidance behavior up to six years after the accident. ${ }^{6}$ Post-traumatic stress symptoms have been shown to be associated with an increased risk of persisting neck pain and reduced working ability after a whiplash injury. ${ }^{11,12}$ Studies have also identified that chronic pain is associated with increased levels of depression and/or depressed mood. Moreover, difficulties in psychosocial functioning with limitations in everyday life may dominate for some time after the injury ${ }^{13}$ In several studies of prognostic factors, female gender has been identified as a factor related to poor recovery; however, since other studies have failed to show any gender differences, the literature seems to be inconsistent.

Our study hypothesizes that subjects might suffer from psychological problems such as depression and post-traumatic stress long after a whiplash injury, and these symptoms could affect different areas of community integration. Because most studies have examined patients seeking healthcare soon after the trauma, it was decided to investigate the rela-
Correspondence: Britt-Marie Stålnacke, Department of Community Medicine and Rehabilitation (Rehabilitation Medicine), Bldg 9A, Umeå University Hospital, Umeå University, SE-901 85 Umeå, Sweden.

E-mail: brittmarie.stalnacke@rehabmed.umu.se

Key words: whiplash injuries, depression, stress disorders, post-traumatic.

Contributions: BMS designed the study, conducted the data analysis, and wrote the paper.

Conflict of interest: the authors report no conflicts of interest.

Received for publication: 23 November 2009. Revision received: 16 February 2010.

Accepted for publication: 17 February 2010.

This work is licensed under a Creative Commons Attribution 3.0 License (by-nc 3.0).

(C) Copyright B-M Stålnacke, 2010

Licensee PAGEPress, Italy

Mental Illness 2010; 2:e4

doi:10.4081/mi.2010.e4

tionships between pain, post-traumatic stress, depression, and community integration in a non-healthcare seeking population five years after a whiplash injury. Additionally, the study aimed to analyze differences in these variables regarding gender.

\section{Materials and Methods}

\section{Patients and procedure}

Information of subjects seeking acute medical assessment because of whiplash trauma within three days after the trauma in the Umea district of Northern Sweden during the year 2001 was collected from the Umeå university hospital injury and trauma register. Exclusion criteria were acute fractures or dislocations of the cervical spine related to a whiplash injury, resulting in the inclusion of persons with WAD grades I-III. ${ }^{1}$ A set of questionnaires was sent to 304 persons eligible for the study, aged 18-64 years old, five years after the injury. After one written reminder, subjects were contacted by telephone if the questionnaires were not returned. In total, 191 persons answered the questionnaires and participated in the study [88 men (46\%) and 103 women (54\%)]; 25 persons actively declined from participating. The mean age of the participants was $32.7 \pm 11.4$ years at the time of injury. Vehicle accidents were the trauma cause in most participants (81\%). The participants were compared with the non-participants (non-responders and the persons who declined 
to participate). Among the non-participants $63 \%$ were men, but no significant difference was found in information about external cause of injury or other information from the trauma register.

\section{Measurements}

Pain intensity was assessed with a visual analogue scale (VAS). ${ }^{14}$ Depression, post-traumatic stress, and community integration were assessed using the Beck depression inventoryII (BDI-II), ${ }^{15}$ the impact of event scale (IES), ${ }^{16}$ and the community integration questionnaire (CIQ). ${ }^{17}$

\section{The visual analogue scale}

Neck pain was reported by $59 \%$ of participants. The VAS was used to rate the pain intensity. The scale consists of a 100 -mm straight line with defined end-points ("no pain" and "worst pain imaginable") on which the participants were asked to mark their experienced pain (results in $\mathrm{mm}$ ) during the previous week. The VAS is considered to have a high degree of reliability and validity. ${ }^{14}$

\section{The impact of event scale}

The IES is a widely used self-report scale. ${ }^{16}$ It is a valid measure of post-traumatic stress reactions and has been suggested as a screening tool for post-traumatic stress disorder (PTSD). The IES comprises seven statements regarding intrusive symptoms and eight regarding avoidance symptoms. A total score can vary from 0 to 80 and the score was divided into four grades from sub-clinical (0-8), mild (9-25), moderate (26-43), to severe (4475) stress reactions.

\section{The Beck depression inventory}

The BDI-II manual is a 21-item self-report of depression over a seven-day period. ${ }^{15}$ The response format ranges from 0 to 3 (with 3 indicating maximal distress). A total score includes all scores and has a range from 0 to 63. The BDI-II scores can be divided into four grades from minimal to severe depression (minimal depression: score 0-13, mild depression: score 14-19, moderate depression: score 20-28, and severe depression: score 29-63). ${ }^{15}$

\section{The community integration ques- tionnaire}

Whiplash injuries have several similarities with concussions or mild traumatic brain injuries. In previous studies the CIQ has been used to assess community integration and the outcome for patients with traumatic brain injuries and also mild traumatic brain injuries or concussions. ${ }^{17,18}$ The CIQ has a total score (range 0-29) and three subscales: social integration (range 0-12), home integration (range $0-10$ ), and productivity (range $0-7$ ). The social

Table 1. Questionnaire response for the total group of patients (means, with standard deviations in parentheses).

\begin{tabular}{lcccc} 
Variables & $\begin{array}{c}\text { All participants } \\
(\%)\end{array}$ & $\begin{array}{c}\text { Women } \\
(\%)\end{array}$ & $\begin{array}{c}\text { Men } \\
(\%)\end{array}$ & $\begin{array}{c}\text { Statistics } \\
\text { P }\end{array}$ \\
Beck depression inventory (BDI-II) & $(\mathrm{n}=175)$ & $(\mathrm{n}=98)$ & $(\mathrm{n}=77)$ & \\
Level of depression & & & & \\
$\quad$ Minimal depression & $137(78)$ & $74(76)$ & $63(82)$ & \\
Mild depression & $21(12)$ & $11(11)$ & $10(13)$ & \\
$\quad$ Moderate depression & $12(7)$ & $9(9)$ & $3(4)$ & \\
$\quad$ Severe depression & $5(3)$ & $4(4)$ & $1(1)$ & 0.354 \\
Total score & $7.59 \pm 8.87$ & $8.09 \pm 9.25$ & $6.96 \pm 8.38$ & 0.663 \\
Impact of event scale (IES) & & & & \\
Level of stress reaction & $(\mathrm{n}=189)$ & $(\mathrm{n}=102)$ & $(\mathrm{n}=87)$ & \\
$\quad$ Sub-clinical & $118(62)$ & $59(68)$ & $59(68)$ & \\
$\quad$ Mild & $43(23)$ & $27(26)$ & $16(18)$ & \\
$\quad$ Moderate & $21(11)$ & $13(13)$ & $8(9)$ & \\
$\quad 7(4)$ & $3(3)$ & $4(5)$ & 0.395 \\
Severe & $36 \pm 13.59$ & $10.75 \pm 13.13$ & $9.78 \pm 14.14$ & 0.692 \\
Total score & $5.21 \pm 6.79$ & $5.40 \pm 7.0$ & $4.93 \pm 6.96$ & 0.905 \\
\hline Antrusion & $5.16 \pm 7.50$ & $5.37 \pm 7.34$ & $4.85 \pm 7.75$ & 0.436 \\
Coidance & $(\mathrm{n}=191)$ & $(\mathrm{n}=98)$ & $(\mathrm{n}=77)$ & \\
\hline Community integration questionnaire & $20.40 \pm 3.69$ & $20.85 \pm 3.71$ & $19.88 \pm 3.61$ & 0.020 \\
Homal score & $5.83 \pm 2.22$ & $6.24 \pm 2.13$ & $5.37 \pm 2.25$ & 0.001 \\
\hline Social integration & $9.13 \pm 1.79$ & $9.29 \pm 1.81$ & $8.94 \pm 1.76$ & 0.160 \\
Productivity & $5.31 \pm 1.58$ & $5.20 \pm 1.75$ & $5.43 \pm 1.37$ & 0.385 \\
\hline
\end{tabular}

integration subscale is composed of items related to socialization with others and activities engaged in outside the home that are rated according to frequency of activity and companionship during the activities. The home integration subscale includes items related to activities in the home, rated on whether the individual performs the activity independently, with another person, or not at all. The productivity subscale is composed of items related to time spent outside the home per week, and includes employment and school activities.

\section{Statistical analysis}

All statistical analyses were performed with SPSS (version 17.0 for Windows; SPSS Inc., Chicago, IL, USA). Data are reported as means \pm standard deviations unless indicated otherwise. Mann-Whitney tests were used to test differences between groups (i.e. as post-hoc tests). Spearman's correlation coefficient was calculated for the analysis of bivariate correlations. The statistical significant level was set at $\mathrm{P}<0.05$ (two-tailed).

\section{Results}

\section{Pain intensity}

Pain intensity on the VAS for all participants five years after the injury was $30.2 \pm 29.1 \mathrm{~mm}$. Women reported statistically significantly $(\mathrm{P}=0.028)$ higher scores $(36.4 \pm 31.7 \mathrm{~mm})$ in comparison with men $(30.2 \pm 29.2)$. A majority of the persons $(62.7 \%)$ rated higher than 10 $\mathrm{mm}$ on the VAS.

\section{Depression}

The BDI-II was answered by 175 persons. The depression levels according to the BDI-II scores are shown in Table 1. Depressive symptoms (one or more) were reported by $74 \%$ of participants. Twenty-two percent of the individuals reported scores that were classified as mild to severe depression. No statistically significant difference was found between men and women on the total score of BDI-II.

\section{Post-traumatic stress}

The IES was answered by 189 persons; $70 \%$ reported the presence of at least one post-traumatic stress symptom. (The levels of post-traumatic stress are shown in Table 1). The most common symptom reported by $54 \%$ of persons was "Other things kept making me think about it" and "I thought about it when I didn't mean to" was reported by $43 \%$. Thirty-eight percent of participants reported mild to severe stress. According to the sub-classification by Kongsted et al., ${ }^{19}$ a mild stress response (subclinical and mild stress reactions) was observed in $85 \%$ of persons and a distinct stress response (moderate and severe stress reactions) was present in $15 \%$. No statistically significant differences were found between men and women with respect to the total IES score or the subscales Intrusion or Avoidance.

\section{Community integration}

Table 1 shows the mean score and standard deviation for CIQ in all subjects with whiplash injury. The total score for all individuals was $20.40 \pm 3.69$ out of a possible 29 . Total scores for 
women were statistically significantly higher $(20.85 \pm 3.71)$ than for men $(19.88 \pm 3.61)$ $(\mathrm{P}=0.020)$. The three subscale scores of the CIQ (social integration, home integration, and productivity) were analyzed separately. Women reported significantly higher levels of home integration $(6.24 \pm 2.13)$ in comparison with men $(5.37 \pm 2.25)(\mathrm{P}=0.001)$ while no significant gender difference was found on the subscales social integration and productivity.

\section{Correlations}

To identify the relationships between pain and psychological variables (depression, posttraumatic stress, and community integration), Spearman's correlate coefficients were calculated (Table 2). A significant correlation was found between pain intensity (total score of VAS) and post-traumatic stress (total score of IES, $r=0.456, P<0.001)$. The total score of VAS was correlated to the BDI-score $(r=0.646$, $\mathrm{P}<0.001$ ), and negatively to the total CIQ-score $(\mathrm{r}=-0.300, \mathrm{P}<0.001)$.

\section{Discussion}

A majority of the non-healthcare seeking subjects in our study reported the presence of neck pain. Pain intensity was high. In almost $63 \%$ of persons the VAS score was higher than $10 \mathrm{~mm}$, which is considered symptomatic. ${ }^{7}$ Most subjects (70\%) reported the presence of at least one post-traumatic stress symptom. Distinct posttraumatic stress was reported in $15 \%$ and mild post-traumatic stress in $85 \%$, results that are in line with the percentages documented early after whiplash injuries. ${ }^{19}$ Mild to severe depression was found in $22 \%$ of participants, and community integration was higher in women than in men. Moreover, pain intensity (total score of VAS) was significantly related to post-traumatic stress and depression and negatively to community integration.

Women reported significantly higher pain intensity than men. Recently, a number of studies have suggested that men and women differ with respect to their perception and experience of pain,,$^{20}$ and lower pain thresholds have been reported in women. ${ }^{21}$ Although only pain intensity was measured in our study, the higher VAS scores in women are in line with previous reports in the literature and may reflect women's total experience of pain.

In our study the post-traumatic stress symptoms on the IES (mild stress in $85 \%$ and distinct stress in $15 \%$ of subjects) were similar to the results documented by Kongsted et al..$^{19}$ early after whiplash injuries (mild stress in $87 \%$, distinct stress in $13 \%$ of participants). Although post-traumatic stress reactions are described several years after traffic accidents and higher levels of post-traumatic stress have been docu-

Table 2. Correlations between VAS, BDI-II, IES, and CIQ scales.

\begin{tabular}{lcccc} 
& VAS & $\begin{array}{c}\text { BDI-II } \\
\text { total score }\end{array}$ & $\begin{array}{c}\text { IES } \\
\text { total score }\end{array}$ & $\begin{array}{c}\text { CIQ } \\
\text { total score }\end{array}$ \\
VAS & & 0.646 & 0.456 & -0.300 \\
BDI-II total score & 0.646 & & 0.547 & -0.237 \\
\hline IES total score & 0.456 & 0.547 & & -0.112 \\
CIQtotal score & -0.300 & -0.237 & -0.112 & \\
\hline
\end{tabular}

mented in persons who suffer from pain, ${ }^{22}$ the rate of post-traumatic stress reactions after whiplash injuries might be underestimated. Therefore, the importance of diagnosis and treatment of post-traumatic stress early after a whiplash injury in order to reduce the risk of long-lasting symptoms has been proposed. ${ }^{23}$ Psychological problems may also include symptoms of depression, which is commonly reported after whiplash injuries. ${ }^{24}$ However, it is difficult to compare the results between different studies as a number of separate questionnaires to measure depression are reported in the available literature. In our study, the result of mild to severe depression (22\%) on the BDI-II was in line with the proportion previously reported in whiplash patients three years after injury (24\%). ${ }^{25}$ Together these findings show that the levels of depression in the chronic stage probably do not decrease and may persist.

We examined community integration using the CIQ, which has been used in quantifying the measuring of rehabilitation outcomes in patients with concussion or mild traumatic brain injury. ${ }^{18}$ Since there are several similarities regarding chronic symptoms after whiplash injuries and concussion or mild traumatic brain injuries, and there are people who may sustain both whiplash injury and concussion at the same trauma, the assessment of community integration after whiplash injury might be of interest. The CIQ score of the subjects in our study was in the same range as that reported for persons with concussion both early and several years after the injury. ${ }^{18,26}$ In comparison with healthy individuals, the productivity sub-scale scores of the subjects in our study were clearly lower. ${ }^{27}$ The productivity sub-scale includes occupational items. The low scores therefore might depend on decreased ability to work or study. In accordance with previous studies of persons with chronic symptoms after concussion, females reported significantly higher sub-scores of home integration than males. ${ }^{18,28}$ This gender sensitivity may depend on the general social patterns of gender roles, which may also have contributed to the significant difference between men and women in our study. Since no significant difference between genders was found on the sub-scale social integration, this finding implies that both men and women had the same levels of social contacts and personal relationships. However, neither the quantity nor the quality of social networks is documented by the sub-scale social integration, factors that may be import for perceived health.

There are few studies of the long-time outcome after whiplash injuries. However, psychological complications have been shown in traffic accident victims up to five years after the trauma. ${ }^{6}$ In our study, relationships between pain intensity and psychological factors were investigated and strong correlations were demonstrated between pain intensity and post-traumatic stress, pain intensity and depression, and negatively between pain intensity and community integration. These findings indicate that people who experience high pain intensity after whiplash injury may also suffer from high levels of post-traumatic stress and depression that parallel a decrease in community integration. Previous research has shown that whiplash patients with persistent symptoms commonly report consequences in daily life including decreased activity levels. ${ }^{29}$ Since the combination of pain, post-traumatic stress, and depression may affect several areas, it seems reasonable to assume that people who suffer from all these symptoms might experience difficulties with both home and occupational activities as well as with social contacts and relationships. Several studies have reported the complex interaction of physical, psychological, and psychosocial factors in chronic WAD, ${ }^{30,31}$ and a biopsychosocial model is often used to describe the multifactorial nature of the condition in persons with chronic pain after whiplash injury. ${ }^{32,33}$

Several limitations of our study should be noted. Out of the 304 subjects who were eligible for the study, only 191 had completed the questionnaires and 25 actively declined to participate. One possible explanation might be the demographic structure of the geographical area with a rather young population. However, there were no differences between participants and non-participants regarding information about external cause of injury or other information from the injury and trauma register. Previous studies have pointed out selection bias. For example, many long-term studies of whiplash injuries are based on patients seeking healthcare because of prolonged symptoms or on data from insurance companies. Our study was based on a well-defined population; the Umeå University Hospital is the only hospital and medical faculty in the city. Most people suffering from whiplash injuries seek acute medical care at the hospital emergency department. 
Both inpatients and outpatients from the area are treated and the general practitioner on call is located at the hospital. Moreover, because the questionnaires used are validated and the participants referred reported symptoms associated with whiplash injury, the subject's reported self-experienced situation five years after the injury seems to be reliable. However, there may be symptoms of other origins that occur during the follow-up period; therefore, we cannot rule out systematic distortions as other factors might have influenced the subjects' results. There was a lack of pre-injury information regarding chronic pain and medication and there was no psychiatric interview included in the study. Pain might fluctuate after a whiplash injury, but a considerably high proportion (63\%) of the participants reported symptomatic pain intensity in comparison with the frequency of neck pain previously reported in the general population ( $23 \%$ women, $15 \%$ men) ${ }^{34}$

We concluded that our results indicate that a significant proportion of participants experience both pain and psychological difficulties a long time after a whiplash injury, particularly post-traumatic stress and depression. These findings should be taken into consideration in the management of subjects with chronic WAD and may support a multi-professional rehabilitation model after a whiplash injury that integrates physical, psychological, and psycho social factors.

\section{References}

1. Spitzer WO, Skovron ML, Salmi LR, et al. Scientific monograph of the Quebec Task Force on Whiplash-Associated Disorders: redefining "whiplash" and its management. Spine 1995;20:S1-73.

2. Sterner Y, Toolanen G, Gerdle B, et al. The incidence of whiplash trauma and the effects of different factors on recovery. J Spinal Disord Tech 2003;16:195-9.

3. Bjornstig U, Hildingsson $\mathrm{C}$, Toolanen G. Soft-tissue injury of the neck in a hospital based material. Scand J Soc Med 1990;18: 263-7.

4. Hildingsson C, Toolanen G. Outcome after soft-tissue injury of the cervical spine. A prospective study of 93 car-accident victims. Acta Orthop Scand 1990;61:357-9.

5. Haldorsen T, Waterloo K, Dahl A, et al. Symptoms and cognitive dysfunction in patients with the late whiplash syndrome. Appl Neuropsychol 2003;10:170-5.

6. Mayou R, Tyndel S, Bryant B. Long-term outcome of motor vehicle accident injury. Psychosom Med 1997;59:578-84.

7. Kyhlback M, Thierfelder T, Soderlund A. Prognostic factors in whiplash-associated disorders. Int J Rehabil Res 2002;25:181-7.

8. Radanov BP, di Stefano G, Schnidrig A, et al. Role of psychosocial stress in recovery from common whiplash. Lancet 1991;338: 712-5.

9. Levin HS, Brown SA, Song JX, et al. Depression and posttraumatic stress disorder at three months after mild to moderate traumatic brain injury. J Clin Exp Neuropsychol 2001;23:754-69.

10. Ursano RJ, Fullerton CS, Epstein RS, et al. Acute and chronic posttraumatic stress disorder in motor vehicle accident victims. Am J Psychiatry 1999;156:589-95.

11. Richter M, Ferrari R, Otte D, et al. Correlation of clinical findings, collision parameters, and psychological factors in the outcome of whiplash associated disorders. J Neurol Neurosurg Psychiatr 2004; 75:758-64.

12. Baltov P, Cote J, Truchon M, et al. Psychosocial and socio-demographic factors associated with outcomes for patients undergoing rehabilitation for chronic whiplash associated disorders: a pilot study. Disabil Rehabil 2008;30:1947-55.

13. Palyo SA, Beck JG. Post-traumatic stress disorder symptoms, pain, and perceived life control: associations with psychosocial and physical functioning. Pain 2005;117:121-7.

14. Price DD, Bush FM, Long S, et al. A comparison of pain measurement characteristics of mechanical visual analogue and simple numerical rating scales. Pain 1994;56:21726.

15. Beck AT, Steer RA, Brown GK. Beck Depression Inventory. 2nd edn. Manual, Swedish version. Sandviken: Psykologiförlaget; 2005.

16. Horowitz M, Wilner N, Alvarez W. Impact of Event Scale: a measure of subjective stress. Psychosom Med 1979;41:209-18.

17. Willer BRM, Kreutzer JS, Gordon WA, et al. Assessment of community integration following rehabilitation for traumatic brain injury. J Head Trauma Rehabil 1993;8:7587.

18. Stalnacke BM. Community integration, social support and life satisfaction in relation to symptoms 3 years after mild traumatic brain injury. Brain Inj 2007;21:93342.

19. Kongsted A, Bendix T, Qerama E, et al. Acute stress response and recovery after whiplash injuries. A one-year prospective study. Eur J Pain 2008;12:455-63.

20. Bernardes SF, Keogh E, Lima ML. Bridging the gap between pain and gender research: a selective literature review. Eur J Pain 2008;12:427-40.

21. Rolke R, Baron R, Maier C, et al. Quantitative sensory testing in the German Research Network on Neuropathic Pain (DFNS): standardized protocol and refer- ence values. Pain 2006;123:231-43.

22. Roth RS, Geisser ME, Bates R. The relation of post-traumatic stress symptoms to depression and pain in patients with accident-related chronic pain. J Pain 2008;9: 588-96.

23. Jansen GB, Edlund C, Grane P, et al. Whiplash injuries: diagnosis and early management. The Swedish Society of Medicine and the Whiplash Commission Medical Task Force. Eur Spine J 2008;17: S355-417.

24. Peolsson M, Borsbo B, Gerdle B. Generalized pain is associated with more negative consequences than local or regional pain: a study of chronic whiplash-associated disorders. J Rehabil Med 2007;39:260-8.

25. Miettinen T, Leino E, Airaksinen 0, et al. Whiplash injuries in Finland: the situation 3 years later. Eur Spine J 2004;13:415-8.

26. Winkler D, Unsworth C, Sloan S. Factors that lead to successful community integration following severe traumatic brain injury. J Head Trauma Rehabil 2006;21:821.

27. Hall KM, Bushnik T, Lakisic-Kazazic B, et al. Assessing traumatic brain injury outcome measures for long-term follow-up of community-based individuals. Arch Phys Med Rehabil 2001;82:367-74.

28. Dijkers MP. Measuring the long-term outcomes of traumatic brain injury: A review of the Community integration questionnaire. J Head Trauma Rehabil 1997;12:74-91.

29. Bunketorp L, Nordholm L, Carlsson J. A descriptive analysis of disorders in patients 17 years following motor vehicle accidents. Eur Spine J 2002;11:227-34.

30. Radanov BP, Sturzenegger M, Di Stefano G. Long-term outcome after whiplash injury. A 2-year follow-up considering features of injury mechanism and somatic, radiologic, and psychosocial findings. Medicine (Baltimore) 1995;74:281-97.

31. Sullivan MJ, Stanish W, Sullivan ME, et al. Differential predictors of pain and disability in patients with whiplash injuries. Pain Res Manag 2002;7:68-74.

32. Gatchel RJ, Peng YB, Peters ML, et al. The biopsychosocial approach to chronic pain: scientific advances and future directions. Psychol Bull 2007;133:581-624.

33. McLean SA, Clauw DJ, Abelson JL, et al. The development of persistent pain and psychological morbidity after motor vehicle collision: integrating the potential role of stress response systems into a biopsychosocial model. Psychosom Med 2005;67:783-90.

34. Guez M, Hildingsson C, Nilsson M, et al. The prevalence of neck pain: a populationbased study from northern Sweden. Acta Orthop Scand 2002;73:455-9. 